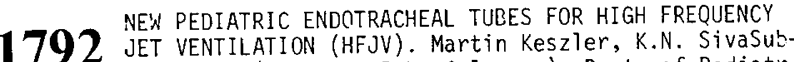
ramanian, (Spon. by P.L. Calcagno). Dept. of Pediatr town University Medical Center, Washington, D.C.

ics, Georgetown Universion An uncuffed intramural jet channel for distal gas delivery was tube with an intramal delivery system (a metal cannula aimed at compared to a proximal delivery system a metal cannula aimed at the ET tube orifice from a distance of $1-2 \mathrm{~mm}$ to avoid obstruct

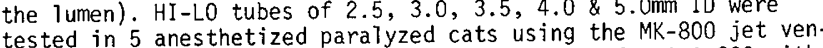
tilator, duty cycle of $30 \%$, FIO2 of 1.0 , rates of $150 \& 300$ with tilator, duty cycliant lungs. The IDs of the metal cannula \& the HI-10 tube jet channel were matched. Driving pressure was adjusted to maintain constant mean airway pressure for each pair. Under al to maintain constant reastems provided equally effective oxygenation conditions the two systems provided equal-D).

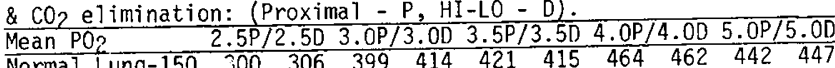
\begin{tabular}{lllllllllll} 
Norma 1 Lung-150 & 300 & 306 & 399 & 414 & 421 & 415 & 464 & 462 & 442 & 447 \\
\hline Nor & 302 & 379 & 385 & 448 & 451 & 453 & 440 & 403 & 421
\end{tabular} $\begin{array}{lllllllllll}\text { Normal Lung-300 } & 292 & 257 & 379 & 385 & 448 & 451 & 453 & 440 & 403 & 421 \\ \text { Stiff Lung-150 } & 195 & 198 & 193 & 186 & 426 & 423 & 373 & 374 & 339 & 397\end{array}$ $\begin{array}{llllllllllll}\text { Stiff Lung-150 } & 192 & 178 & 186 & 186 & 420 & 413 & 347 & 355 & 328 & 373 \\ \text { Stiff Lung-300 } & 182 & 174 & 186 & 18 & & \end{array}$

\section{Mean $\mathrm{PCO} 2$}

$\begin{array}{lllllllllll}\text { Norma? Lung-150 } & 19 & 19 & 28 & 25 & 21 & 23 & 26 & 28 & 19 & 24\end{array}$

$\begin{array}{lllllllllll}\text { Norma1 Lung-300 } & 23 & 25 & 38 & 40 & 25 & 24 & 33 & 34 & 26 & 26 \\ \text { Stiff Lung-150 } & 31 & 33 & 31 & 33 & 22 & 22 & 27 & 29 & 29 & 27 \\ \text { Stiff Lumg } & & \end{array}$

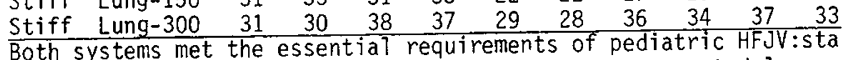
Both systems met the essen channel. The HI-LO tube generated less entrainment. The pressure monitoring channel was useful \& accurate.

LOAD COMPENSATION AND LUNG VOLUME IN NEONATES.

1793 Alfred Krauss, Barbara Lewis, Peter Auld, Corneil Univ. Med. College Dept. of Pediatrics, New York City. The pressure response to mask occlusion was measured in 16 infants between 1 and 45 days of age and $0.9-4.0 \mathrm{~kg}$ in weight. Measurements were made in a body plethysmograph, allowing simultaneous measurements of pressure responses and lung vorume Ancreases in mask pressure ( $(P \max$ ) within 2-3 breaths after occlusion. The maximum pressure and the maximum rate of change in clusion. The maximum pressure and the maximum rate of change in
mask pressure $(\mathrm{dp} / \mathrm{dt})$ were inversely correlated with $\mathrm{Vtg}(\mathrm{r}=-.35)$. Individual infants demonstrated a greater increase in pressure within 3 breaths after occlusion with increasing age in $6 / 10$ of patients studied on muttiple occasions. The degree of load compensation correlated poorly with Vtg $(r=-.26), v \mathrm{tg} / \mathrm{cm}(r=-.22)$, and age $(r=.24)$. Previously published results from this laboratory have demonstrated simultaneous increases in respiratory chemosensitivity in conjunction with increasing maturity and increasing lung volume, while failing to detect significant vagal effects with increasing lung volume. This indicates that
the role of Vtg in regulation of respiration in the newborn infant is to stabilize blood gases and maintain normal mechanical aspects of pulmonary function. The influence of $\mathrm{Vtg}$ on the reflex control of breathing in heal thy preterm and mature human infants is weak. Impulses arising within the central nervous system and modified by the chemoreceptors appear to be the most significant source of respiratory control in human neonates.

$\dagger 1794$ EFFECTIVENESS OF EXTRACTED COW LUNG LIPID (CLL) IN INDUCING AND SUSTAINING NORMAL LUNG FUNCTION IN SURFACTANT DEFICIENT PREMATURE LAMBS. Melinda S. Kwong, Edmund A. Egan, Donald S. Shapiro, Robert H. Notter, Depts. Ped. Sterilized CLL was studied in premature lambs 132-134 days A. to determine if pre-breathing instillation could induce and G. A. to determine if pre-breathing instillation could induce and sustain normal lung function for 2 days. CLL is a chloroform
methanol extract of lavage of calf's lung containing $1 \%$ protein and flash autoclaved for sterility. We delivered 4 fetal lambs by hysterotomy, intubated them, took $10 \mathrm{ml}$ of fetal lung liquid, instilled $100 \mathrm{mg} / \mathrm{kg}$ of CLL in $10 \mathrm{ml}$ of saline, and ventilated them immediately. Three control lambs were treated with $10 \mathrm{ml}$ of saline. The lambs, sedated with nembu: - l, were managed using a clinical protocol. All CLL animals survived for $36-48$ hours a clinical protocol. Two control animals had a pneumothorax and in good condition. Two control animals had a pneumothorax died at 21 hours. CLL treated lambs required mean al way pressures (MAP) of $10-15 \mathrm{~cm} \mathrm{H2O}$ for 2 hours; average MAP was $\leq 10 \mathrm{~cm} H 20$ thereafter to maintain a $\mathrm{PaCO} 2 \quad 30-45$. Control
animals required an average MAP $>20 \mathrm{~cm} \mathrm{H} 20$ for 2 hours and 10-20 $\mathrm{cm} \mathrm{H} 20$ thereafter. Fi 02 requi rements became $<.4$ by 7 hours in the $\mathrm{Cl}$ treated lambs. Control lambs required $\mathrm{FiO}>2>4$ until 21 hours age. Lavage of the lung at sacrifice revealed $49+10$ uM treatment before breathing induces and sustains normal lung function for $36-48$ hours. This appears to be a surfactant function for $36-48$ hours. This appears to be a surfactant prepar

(Supported by HL22552 \& HL00945)
BRONCHODILATOR EFFICACY OF ISOETHARINE METHYLATE

1795 ADMINISTERED BY METERED DOSE INHALER (MDI) BY BAC (B) VERSLUS JET NEBULIZER (J).

haesoon Lee, Hugh E. Evans, Interfalth Medical Center/SUNY Downstate Medical Center, Brookiyn, New York.

Beta agonists administered in aerosol form are effective and safe therapy for asthma. MDIs are conventent means of generating aerosols but patients younger than $\sigma$ are unable to learn Inhalation technique. We have developed an aerosol bag of 1.2 liter capacity by modifyling the standard freezer bag (Z1ploc, Dow (nemical) with a mouthpiece attached in the corner. After the bag was inflated and canister activated through the mouthplece, the patient breathed in and out of the bag 10 times (through the mouthplece). We compared the bronchodilator efflcacy of isoetharine aerosol 2 puffs $(0.34 \mathrm{mg}$ per puff) administered from a MDI in the modifled $B$ with $2.5 \mathrm{mg}$ of Isoetharine diluted in $2.5 \mathrm{ml}$ of saline nebulized in a compressed air driven $\mathrm{J}$ in 15 stable asthmatic children ages 8 to 15 . Treatment was given in randomized double blind cross before and after therapy for 4 pulmonary function was tested before and after the mean baseline $F_{1} \mathrm{~S}$ were 1.27 (B) and $1.22(\mathrm{~J})$ liter hours. The mean baseline $\mathrm{FEV}_{1} \mathrm{~S}$ were 1.27 (B) and $1.22(\mathrm{~J})$
and increased $39,41,43,36,21$ and $11 \%$ above the baseline period at $10,30,60,120,180$ and 240 minutes after $B$ and 32 , $33,28,17,7$ and $5 \%$ at the same intervals after $J$. The differences were not significant at any time. Aerosol administered with the $B$ form of MDI is more advantageous than the $J$. It is more convenient, easily portable, and cost effective with lower dose $(0.68 \mathrm{mgm})$ than required with a (J) $(2.5 \mathrm{mg})$.
1796 LACK OF EFFECT ON CARDIAC RHYTHM FROM REPEATED DOSES OF ALBUTEROL AEROSOL (AA) ADMINISTERED FROM A METERED DOSE INHALER (MDI). Haesoon Lee, Hugn E. Evans, Interfalth Medical Center/SUNY vownstate Medical Center, Brookiyn, New York.

Beta agonists administered by aerosol are effective treatment for asthma. They produce prompt, significant bronchodilar tion. Side effects are few but cardiac arrhythmias may occur when the patient exceeds the prescribed dose. Our previous study (J. Peds 103:655, 1983) showed that 2 puffs of AA did not disturb cardiac rinythm. We have now studied the potential effect of frequently repeated inhalation of AA to simulate the pattern of use by some patients at home. 15 stable outpatient asthmatic children ( 9 to 14 years old) were treated with 2 puffs of AA (1s0mcg) ren ( 9 to 14 years o1d) were treated with 2 puffs of AA (lib
followed either by hourly placebo or hourly AA for 5 hours ( 10 puff $s=900 \mathrm{mcgs}$ ) in a randomized, double blind cross over study. Cardiac rhythm was Holter monitored and pulmonary function was tested hourly for $j$ hours. Heart rate (HR) was analyzed at hourly intervals. Pretreatment HR of $95 \mathrm{bpm}$ declined by $1-2 \mathrm{bpm}$ after single dose and simflariy $2-5 \mathrm{bpm}$ from $99 \mathrm{bpm}$ during multiple doses. No one developed arrhythmia and side effects ting multiple doses. No one developed arrhythmias and side equent on either day. FEV 1 increased $35,38,42,41,44$ were infrequent on either day. FEV 1 increased $35,38,42,41$,
and $44 \%$ above the baseline period at $30,60,120,180,240$ and 300 minutes after multiple doses and 36, 40, 38, 33, 27 and $19 \%$ at the same intervals after single dose. The difference was significant $(P<0.05)$ at 240 and 300 minutes. No cardiac toxicity occurred with hourly administration (for Shrs) of AA using MDI. Hence there is apparently a substantial margin of safety in administration of this agent to asthmatic children.
PROGNOSIS OF LEFT VENTRICULAR HYPERTROPHY (LVH) IN

1797 BRONCHOPULMONARY DYSPLASIA (BPD). Lucille A. Lester Dolly Thomas (Spon. by Richard M. Rothberg. The University of Chicago, Department of Pediatrics, Chicago, IL. Cor pulmonale or right ventricular hypertrophy (RVH) is a recognized complication of BPD, while LVH has been reported mainiy at autopsy. Serial cardiac evaluations were performed on 19 infants with BPD during a 2 year period. RVH was documented by EKG and $\mathrm{EHCO}$ (RVH=RV wall thickness >2SD above mean predicted) in 13/ 19 infants; 6/19 had an $\uparrow$ RV dimension and $9 / 19$ had abnormal RV systolic time intervals on at least 1 occasion, suggesting $\uparrow$ pulsystolic time intervals on at least 1 occasion ( 2 SD above mean) was monary artery pressure. $4 V$ wall thickness ( 10 infants. Six of these 10 documented by ECHO in a sub-group of 10 infants. Six of these 10 also had LVH by EKG, and in $7 / 10 \mathrm{LVH}$ was associated with septal
hypertrophy. The LVH was present early and resolved in 2, but persisted or increased in 8 over 4 to 24 months followup. The characteristics for the 2 groups are summarized:

\begin{tabular}{|c|c|c|c|c|c|}
\hline & $\mathrm{n}$ & Birth wgt & Gest. Age & Days ventilated & Outcome \\
\hline $\begin{array}{l}\text { Group I } \\
\text { (LVH) }\end{array}$ & 10 & $\begin{array}{l}1375 \pm 693 \\
\text { grams }\end{array}$ & $\begin{array}{l}30.3 \pm 3.8 \\
\text { wks }\end{array}$ & $64,4 \pm 58$ & $\begin{array}{l}2 \text { died, } 4 \text { chronic } \\
\mathrm{CHF}, 2 \text { home on } \mathrm{O}_{2}\end{array}$ \\
\hline $\begin{array}{ll}\text { Group } & \text { II } \\
\text { (no } & \text { LVH) }\end{array}$ & 9 & $\begin{array}{l}1300 \pm 359 \\
\text { grams }\end{array}$ & $\begin{array}{l}30.3 \pm 2.4 \\
\text { wks }\end{array}$ & $39.3 \pm 31$ & $\begin{array}{l}\text { all home; } \\
5 \text { with } \mathrm{O}_{2}\end{array}$ \\
\hline T-test & $p=n s$ & $p=n s$ & $p=n s$ & $\mathrm{p}=\mathrm{ns}$ & \\
\hline
\end{tabular}

All babies required mechanical ventilation from birth; no significant differences were found in maximum $\mathrm{FiO}_{2}$, peak pressure, or in the mean $\mathrm{PaO}_{2}$ achieved during documented in a subgroup of BPD centric hypextrophy of the lv, documenticated clinical course, prolonged hospitalization, and a poorer prognosis. 